\title{
Unraveling the Role of Ligands in the Hydrogen Evolution Mechanism Catalyzed by [NiFe] Hydrogenases
}

\author{
Siyao Qiu, ${ }^{\dagger}$ Luis Miguel Azofra, ${ }^{\dagger \dagger}$ Douglas R. MacFarlane, ${ }^{*},+\neq$ and Chenghua Sun ${ }^{*},+\neq$ \\ ${ }^{\dagger}$ School of Chemistry, Faculty of Science, Monash University, Clayton, Victoria 3800, Australia \\ ${ }^{\ddagger}$ ARC Centre of Excellence for Electromaterials Science (ACES), School of Chemistry, Faculty of Science, Monash University, \\ Clayton, Victoria 3800, Australia
}

\section{Supporting Information}

ABSTRACT: DFT investigations have been carried out on the hydrogen evolution reaction (HER) mechanism followed by [NiFe] hydrogenases. Calculations on the active site of the $[\mathrm{NiFe}]$ hydrogenase from Desulfovibrio vulgaris str. "Miyazaki $\mathrm{F}$ " reveal that $\mathrm{H}_{2}$ is formed as the final product through the "singlet multiplicity" pathway. Nonspontaneous reaction energies can be seen for both $\mathrm{H}^{+} / \mathrm{e}^{-}$additions to the reactive sulfur atom from the truncated cysteine residues, being the limiting steps of the whole reaction. In contrast, transfers toward the metal environment to produce the bridging hydride and the bonded $\mathrm{H}_{2}$ molecule at the $\mathbf{N i}-\mathbf{C}$ and $\mathbf{I} 2$ steps, respectively, are spontaneous processes. Our DFT results highlight the role of the ligands attached to both the $\mathrm{Ni}$ and $\mathrm{Fe}$ centers. When the protein ligand environment is spatially confined, reaction energies for the HER are lower than those when the ligand carbons are able to freely adjust. In addition, larger changes can be seen on interchanging the $[\mathrm{CN}]^{-}$and $\mathrm{CO}$ ligands on the Fe center; in particular, the energy profile dramatically changes as $[\mathrm{CN}]^{-}$ligands are replaced by $\mathrm{CO}$. These results may guide materials synthesis efforts toward optimized HER catalysts.

KEYWORDS: $\mathrm{H}_{2}$ production, spin effect, enzymatic catalysis, bimetallic enzymes, DFT

\section{INTRODUCTION}

Due to the serious environmental issues stemming from the burning of hydrocarbon compounds based on fossil fuels as energy sources, ${ }^{1-3}$ dihydrogen $\left(\mathrm{H}_{2}\right)$ is emerging as a promising environmentally friendly alternative. However, the high cost of the most active (usually noble metal) catalysts, such as platinum, ${ }^{4}$ creates a real limitation. In this regard, the search for novel catalysts based on only earth-abundant materials is highly desirable. Thus, the challenge lies in finding catalysts that are commercially effective and chemically efficient. ${ }^{5}$

If one candidate attracts much of our attention, undoubtedly, hydrogenase enzymes, representing how Nature produces (or cleaves) $\mathrm{H}_{2}$, have not only shown impressive catalytic performance for dihydrogen production but also are based on abundant metals. ${ }^{6}$

On the basis of the metal centers composing the active site, hydrogenase enzymes (hereafter simply referred as hydrogenases), can be classified into $[\mathrm{NiFe}],[\mathrm{FeFe}]$, or $[\mathrm{Fe}]$ types. ${ }^{7,8}$ Only bimetallic $[\mathrm{NiFe}]$ and $[\mathrm{FeFe}]$ hydrogenases catalyze the reversible reaction of dihydrogen oxidation into protons and electrons, and $[\mathrm{NiFe}]$ hydrogenases have better $\mathrm{O}_{2}$ tolerance than the $[\mathrm{FeFe}]$ species. ${ }^{9}$ Thus, the study of $[\mathrm{NiFe}]$ hydrogenases is of crucial importance for the development of bioinspired catalysts.

With the exception of the $[\mathrm{NiFeSe}]$ subclass, the active sites of the $[\mathrm{NiFe}]$ hydrogenases all have a similar atomic composition: a bimetallic four-membered ring connects $\mathrm{Ni}$ and Fe metal centers via two sulfur atoms; the latter are part of cysteine residues from the protein environment. ${ }^{10}$ Finally, two exocyclic cysteine residues are bound to the Ni through their sulfur atoms and $\mathrm{Fe}$ is linked with three inorganic ligands, one neutral carbonyl and two cyanide anions, via the $\mathrm{C}$ moiety in all cases (see Scheme 1). ${ }^{11}$ In this regard, the structural environment of the Fe ligands has been studied by comparison of quantum chemical calculations of three different configuration models with X-ray and Fourier transform infrared (FTIR) spectroscopy data. ${ }^{12}$

When they are placed in an aerobic environment, $[\mathrm{NiFe}]$ hydrogenases will turn to inactive states. The so-called Ni-A and Ni-B states have the active site blocked by the presence of the $\mathrm{OH}^{-}$species acting as bridging moieties between the two metals, as proposed in the literature. ${ }^{13-19}$ However, under an $\mathrm{H}_{2}$ atmosphere, the $[\mathrm{NiFe}]$ hydrogenase can be reactivated.

According to FT-IR and electron paramagnetic resonance (EPR) spectroscopy, there are three observed active redox states of the $[\mathrm{NiFe}]$ hydrogenases: $\mathrm{Ni}-\mathrm{SI}_{\mathbf{a}}, \mathrm{Ni}-\mathrm{C}$, and $\mathrm{Ni}$ $\mathbf{R}^{20-24}$ which have been studied by comparison of computational and experimental approaches. According to previous

Received: May 15, 2016

Revised: June 27, 2016

Published: July 1, 2016 
Scheme 1. Hydrogen Evolution Reaction (HER) Path Followed by [NiFe] Hydrogenases

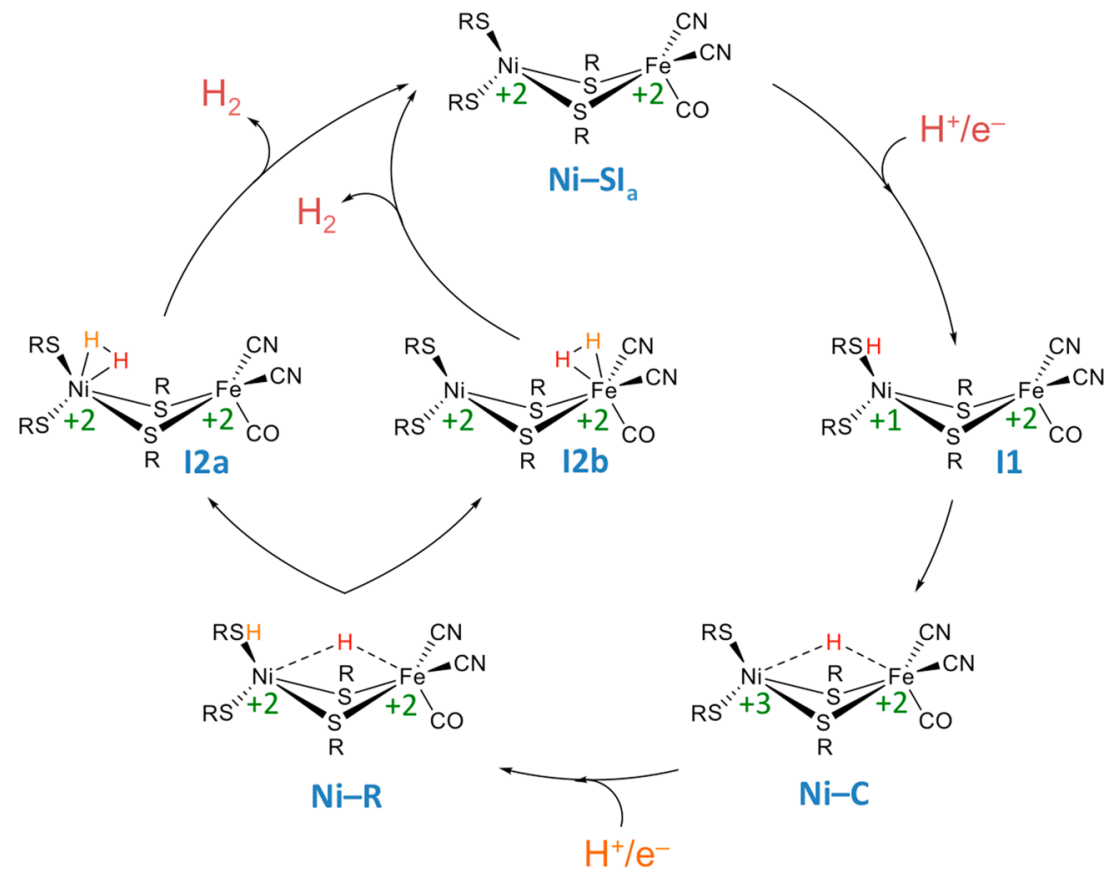

work presented by Siegbahn et al., ${ }^{25}$ Scheme 1 summarizes the corresponding hydrogen evolution reaction (HER) path followed by $[\mathrm{NiFe}]$ hydrogenases; however, a different proposal was previously besought by Niu and co-workers, ${ }^{26}$ consisting of postulating an additional proton binding on the exocyclic sulfur in all reaction states.

Following the HER path gathered in Scheme 1, Ni-SI represents the oxidized active state in which a vacant position exists above the four-membered ring. This active site becomes occupied by a hydride in the Ni-C state. ${ }^{15,27-32}$ I1 is an intermediate state, ${ }^{33}$ during which the first hydrogenation takes place on the sulfur atom of one of the exocyclic cysteine residues directly bonded to $\mathrm{Ni}$, to be finally transferred as a bridging hydride shared between the $\mathrm{Ni}$ and $\mathrm{Fe}$ metals. After the first hydrogenation, the addition of a second $\mathrm{H}^{+} / \mathrm{e}^{-}$pair leads to the Ni-R state. FT-IR spectroscopy indicates the existence of three subforms for this case, ${ }^{34,35}$ and recent X-ray crystallography data and computational studies have verified the persistence of the bridging hydride between the two metal ions and the inclusion of the second $\mathrm{H}^{+} / \mathrm{e}^{-}$pair on the previously reacted terminal sulfur ligand in one of the subforms. ${ }^{36}$ In addition, another recent work by Ogata and co-workers supported the bridging hydride existence by the vibrational spectroscopy for the first time. ${ }^{37}$ As an intermediate state, I2 links the $\mathbf{N i}-\mathbf{R}$ and $\mathbf{N i}-\mathbf{S I}_{\mathbf{a}}$ states, involving the migration of the second proton and first hydride toward the metal centers. ${ }^{29,38}$ These two hydrogen atoms may bind to the $\mathrm{Ni}(\mathbf{I 2 a})$ or to the $\mathrm{Fe}(\mathbf{I} \mathbf{2 b})$ atoms and represent the final steps before the release of $\mathrm{H}_{2}$ as the product. In addition, Mössbauer spectroscopy indicates that the $\mathrm{Fe}$ atom remains doubly positively charged along the entire reactive process, ${ }^{39}$ while $\mathrm{Ni}$ experiences a "charge route" of $+2,+1$, and +3 along the $\mathbf{N i}-\mathbf{S I}_{\mathbf{a}} / \mathbf{I} \mathbf{1} / \mathbf{N i}-\mathbf{C}$ steps.

A variety of studies of the ligand environment of the active sites of the various states discussed above have been published. ${ }^{14,39-44}$ The multiplicity of the $\mathrm{Ni}$ metal is an important question, as both the high-spin ${ }^{45}$ and low-spin ${ }^{46,47}$ states are supported by experimental results. In this regard,
DFT investigations indicate that the BP86 functional exhibits an energy preference for the singlet state, while B3LYP suggests the contrary: that triplet states dominate the reaction path for the Ni-SI and Ni-R states. ${ }^{48}$ According to previous work, BP86 has a smaller mean unsigned error in describing the hydrogenase structures, but more remarkably, accurate ab initio coupled cluster CCSD calculations show an energy preference for the singlet state, being $\sim 14 \mathrm{kcal} / \mathrm{mol}$ more stable than the triplet, for the $\mathbf{N i - S I}$ state. $^{49}$ This is significant, as the multiplicity strongly affects the $\mathrm{H}_{2}$ binding position on the active site: while $\mathrm{H}_{2}$ tends to bind at $\mathrm{Ni}$ in the singlet state, when the multiplicity is triplet, it tends to bind on Fe. ${ }^{50}$

Finally, while it is widely accepted that the ligand environment affects the reaction pathway, the details and origins of the effects remain unclear. In the present work, models with different truncated cysteine ligands are compared in order to study how the proximal protein environment affects the reaction pathway. We pay special attention to how the confinement of the ligands influences the energy profile. In addition, the effects of neutral $\mathrm{CO}$ vs negatively charged $[\mathrm{CN}]^{-}$ ligands are studied.

\section{COMPUTATIONAL DETAILS}

The geometry and properties of the HER mechanism followed by $[\mathrm{NiFe}]$ hydrogenases have been studied through the use of density functional theory (DFT) via the BP86 functional ${ }^{51,52}$ in its unrestricted formalism. Two-layer "onion" basis sets have been applied for all models, using the Def2TZVPP effective core potential for the active site (constituted by the metals, sulfurs, and ligands attached to the Fe atom) and the smaller Def2SVP effective core potential for the carbon chains directly bonded to sulfurs. ${ }^{53}$ In all cases, the EDIIS/CDIIS procedure was applied for the self-consistent field (SCF) convergence. ${ }^{54}$ In addition, frequency calculations were performed in order to confirm the nature of the stationary points and to obtain the zero-point energy ( $\mathrm{ZPE}$ ) as well as the thermal correction terms. Therefore, all the energies reported below are Gibbs free 


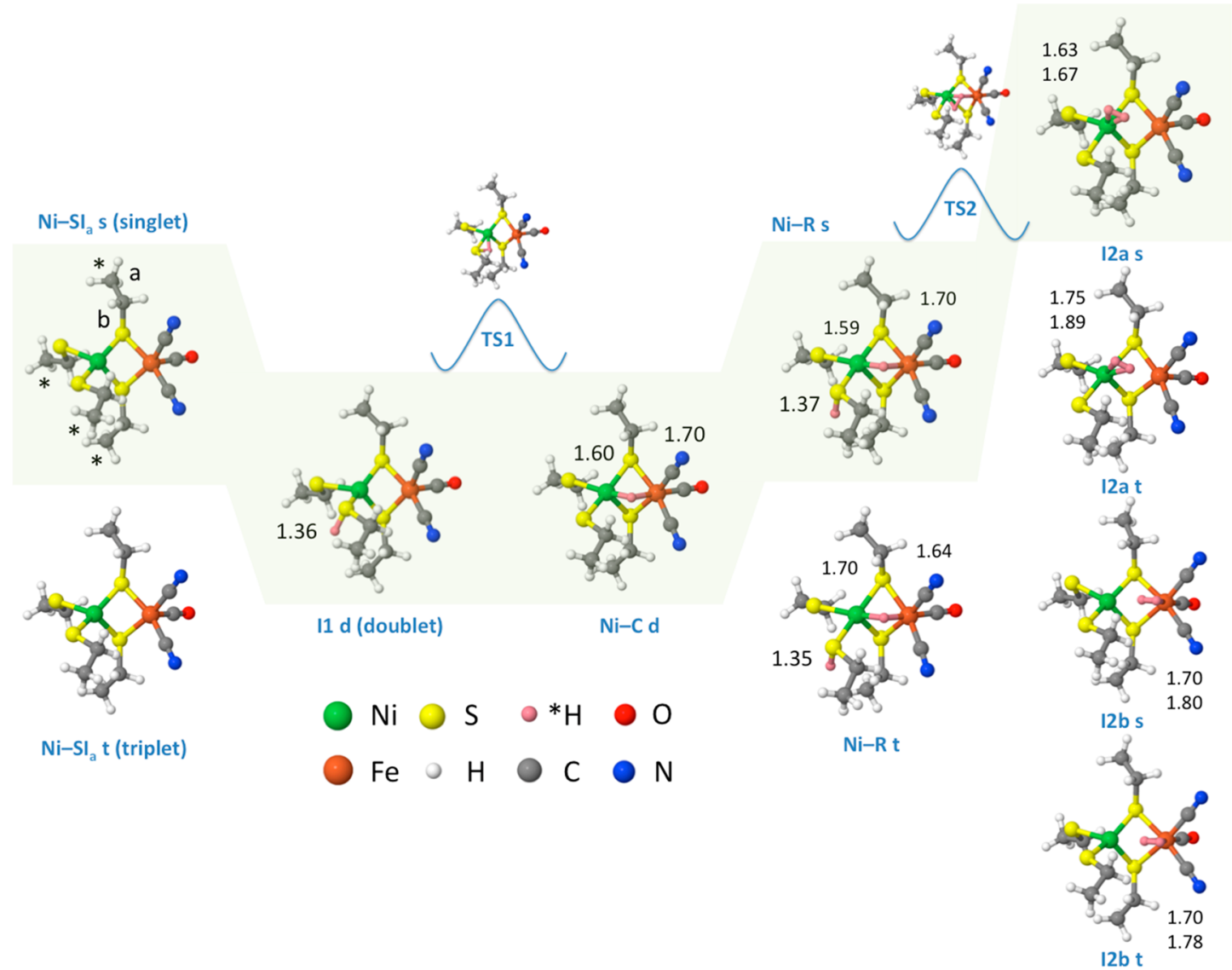

Figure 1. Modeling the HER mechanism steps followed by the [NiFe] active site. Hydrogen atoms participating in the HER pathway are highlighted in pink. Shading indicates the singlet pathway. Frozen carbon atoms are indicated with asterisks at the Ni-SI $\mathbf{a}_{\mathbf{a}}$ singlet state; these carbons are frozen throughout the rest of the structures. Selected H-X distances are shown in Å.

energies under mild conditions. In addition, the dispersion interaction correction has been included during geometry optimization by using Grimme's D3 damping function in all models. ${ }^{55}$ Under $f\left(\mathrm{H}_{2}\right)=101325 \mathrm{~Pa}$ and $\mathrm{pH} 0$ conditions, the energy difference for the $\mathrm{H}^{+} / \mathrm{e}^{-}$added step in this work could be approximated as half of the free energy of the $\mathrm{H}_{2}$ molecule referring to the standard hydrogen electrode ( $\mathrm{SHE}$ ): that is, $G\left(\mathrm{H}^{+}+\mathrm{e}^{-}\right)=1 / 2\left[G\left(\mathrm{H}_{2}\right)\right]$ vs SHE. ${ }^{4,56-58}$ Since the physiological environment presents $\mathrm{pH}$ conditions at around 7, the $\mathrm{pH}$ effect for the $\mathrm{H}^{+} / \mathrm{e}^{-}$added steps on the free energy can be corrected as $\Delta G_{\mathrm{rxn}}=\Delta G^{\circ}+2.303 R T \times \mathrm{pH}$ according to the Nernst equation, resulting in a factor of $+9.55 \mathrm{kcal} / \mathrm{mol}$ at $\mathrm{pH}$ 7. All calculations were carried out through the facilities provided by the Gaussian09 package (revision D.01). ${ }^{59}$

Models used in the present study have been built on the basis of the X-ray crystallographic structure of the reduced [NiFe] hydrogenase from Desulfovibrio vulgaris str. "Miyazaki F" organism (PDB accession code $1 \mathrm{H} 2 \mathrm{R})^{60}$ provided by Higuchi et $\mathrm{al}^{61}$

With the aim of studying the effect of the ligands, two strategies have been followed. On the one hand, free, partially frozen, and totally frozen carbon atoms in the protein ligands have been imposed during optimizations.

On the other hand, the nonprotein $\mathrm{CO}$ and $[\mathrm{CN}]^{-}$ligands attached to the Fe moiety have been replaced by each other in the partially frozen model, while considering the possible influence by the interaction between the inorganic ligands and the surrounding amino acids through hydrogen bonding: Pro478, Leu482, Pro501, and Ser502 residues have been also included in the model. This treatment can discern the key effect played by the ligands, according to their protein or nonprotein nature, showing in some cases important effects in the ratedetermining steps of the dihydrogen production mechanism.

\section{RESULTS AND DISCUSSION}

Reaction Pathway: Spin Preference in the HER Mechanism. In order to understand how $\mathrm{H}_{2}$ is produced on hydrogenases, different paths based on different multiplicity states have been studied (see Figure 1). For this purpose, our truncated model has been built from the X-ray structure of the reduced $[\mathrm{NiFe}]$ hydrogenase from Desulfovibrio vulgaris, ${ }^{60,61}$ retaining the bimetallic $[\mathrm{NiFe}]$ active sites as well as the proximal functional groups around them. Finally, with the aim of retaining the enzymatic structure-reactivity pattern, the distal carbon atoms derived from the truncated cysteine residues have been frozen (indicated by asterisks in Figure 1).

In an overall view of the mechanism, while singlet and triplet states can be described for the Ni-SI $\mathbf{I}_{\mathfrak{a}} \mathbf{N i - R}$, and $\mathbf{I} 2$ steps, only doublet multiplicity can be seen for the I1 and Ni-C structures, as a result of the odd number of electrons for these radical states. For the singlet and triplet states of $\mathbf{I} 2$, both the $\mathrm{Ni}-\mathrm{H}_{2}$ and $\mathrm{Fe}-\mathrm{H}_{2}$ states have been hypothesized as stable states. This is slightly different with respect to the results obtained by Bruschi et al., ${ }^{50}$ who described stable structures for $\mathbf{1 2 a}$ in both spin states and showed $\mathbf{I} \mathbf{2} \mathbf{b}$ as unstable with singlet multiplicity. Since their and our works are based on a quite similar level of theory (same BP86 functional), this divergence could be caused 


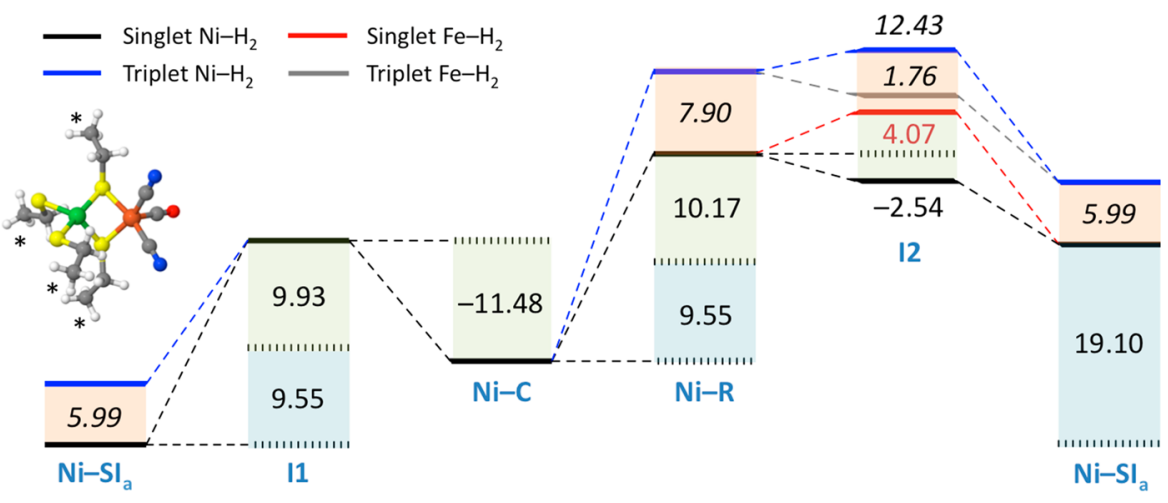

Figure 2. Gibbs free energy profile, in units of $\mathrm{kcal} / \mathrm{mol}$, for the HER path analyzing the spin effect. All energies are referred to that of the Ni-SI state. Energy differences between singlet and triplet states are shown in italics and highlighted in orange. Energy data under standard conditions $\left(f\left(\mathrm{H}_{2}\right)=101325 \mathrm{~Pa}\right.$ and $\left.\mathrm{pH} 0\right)$, under which the $\mathrm{H}^{+} / \mathrm{e}^{-}$injection can be approximated as $G\left(\mathrm{H}^{+}+\mathrm{e}^{-}\right)=1 / 2\left[G\left(\mathrm{H}_{2}\right)\right]$ vs SHE, are presented in green. For the natural environment of hydrogenases $(\mathrm{pH} 7), \mathrm{pH}$ corrections are also included in the energy profile, highlighted in blue.

by the size of the models; however, recent investigations carried out by us on a large model (similar to Bruschi's model: 180 atoms, including the subsequent protein cell around the active site) demonstrate similar results with respect to the different spin states at I2. This leads us to conclude that this divergence might be due to the different protein environment imposed by the kind of $[\mathrm{NiFe}]$ hydrogenases studied: in the case of Bruschi's work, Allochromatium vinosum; in our case, Desulfovibrio vulgaris. Nevertheless, the dihydrogen binding positions at $\mathrm{Ni}$ singlet and $\mathrm{Fe}$ triplet states are consistent with previous works. $^{29,50}$

An analysis in detail of the mechanism indicates that the first $\mathrm{H}^{+}$gain is carried out on one of the sulfur atoms from the truncated cysteine residues directly linked to $\mathrm{Ni}$ (I1). An interatomic $\mathrm{S}-\mathrm{H}$ distance equal to $1.36 \AA$ is obtained at this computational level. The mechanism shown in Scheme 1 indicates that during this first step the electron injected goes to the Ni metal, modifying its charge state. The second step involves the $\mathrm{H}$ transferring from this position to become a bridging hydride shared on the NiFe bimetallic active site (NiC). It is hypothesized that, during this migration, $\mathrm{H}^{+}$becomes $\mathrm{H}:{ }^{-}$by the acquisition of two electrons from $\mathrm{Ni}$, modifying its charge state. ${ }^{62}$ Interatomic distances between hydride and the metals are observed to be 1.60 and $1.70 \AA$ for $\mathrm{Ni}$ and $\mathrm{Fe}$, respectively. The aforementioned $\mathrm{H}^{+} / \mathrm{e}^{-}$gain during the $\mathbf{I} \mathbf{1}$ and $\mathrm{Ni}-\mathrm{C}$ steps distorts the four-membered-ring structure: e.g., the $\mathrm{S}-\mathrm{Ni}$ distance is elongated by approximately 0.02 and $0.09 \AA$, respectively. In addition, dihedral $\varphi_{\mathrm{NiSSFe}}$ angles experience distortions of around $2.1^{\circ}$.

Singlet multiplicity seems to be more stable for the totally reduced Ni-SI $\mathbf{a}_{\text {a }}$ structure, i.e. without $\mathrm{H}$ adding at the beginning; this trend is also present for the subsequent third and fourth steps, in the Ni-R and $\mathbf{I} 2$ structures. In other words, the minimum energy path for the HER mechanism followed by the active site in our [NiFe] hydrogenase model follows a singlet route (highlighted in light green in Figure 1). Previous work by Prabha et al. suggests that the singlet state demonstrated instability between the restricted and unrestricted DFT calculations; however, such a phenomenon could not be seen in this work. ${ }^{63}$

Thus, the Ni-R step represents the second $\mathrm{H}^{+} / \mathrm{e}^{-}$gain taking place on the previously protonated $\mathrm{S}$ atom. Despite the $\mathrm{S}-\mathrm{H}$ distance in the triplet state being smaller than that in the singlet (1.35 vs. $1.37 \AA$ ), this difference seems to be insufficient to modify the singlet minimum energy path identified previously.
Impressively, the multiplicity state strongly affects the coordination environment of the hydride moiety. In the singlet state the proximal hydride-metal distance is to $\mathrm{Ni}(1.59 \AA)$, and in the case of the triplet this is to $\mathrm{Fe}(1.64 \AA)$. However, the sum of both $\mathrm{Ni}-\mathrm{H}$ and $\mathrm{Fe}-\mathrm{H}$ distances are larger in $\mathbf{N i}-\mathbf{R ~ t}$ than in $\mathbf{N i}-\mathbf{R} \mathbf{s}$ ( $\mathbf{t}$ and $\mathbf{s}$ indicating triplet and singlet, respectively).

At this point, it deserves to be mentioned that the possible intermediate stable state between $\mathbf{N i}-\mathbf{R}$ and $\mathbf{I 2}$, in which the proton goes to $\mathrm{Ni}$ or $\mathrm{Fe}$, has been also calculated. ${ }^{50}$ Such a state has been confirmed by both BP86 and B3LYP functionals; ${ }^{51,52,64}$ however, while the energy of this state is almost the same as that for the $\mathbf{I} 2$ state (just representing minor structural reordering), it has therefore not been included in the energy profile.

Focusing on the singlet minimum energy path, the addition of both $\mathrm{H}^{+} / \mathrm{e}^{-}$pairs to the reactive sulfur $\left(\mathrm{Ni}-\mathrm{SI}_{\mathrm{a}}\right.$ to $\mathbf{I 1}$ and NiC to Ni-R) practically does not affect the distance between this $\mathrm{S}$ and $\mathrm{Ni}$ but increases the distance between the nonreactive lower endocyclic sulfur atom and the metals; this is important as the reaction evolves. Increments of 0.09 and $0.23 \AA$ can be seen, in each case. Notwithstanding this, the metal-containing ring is regenerated once the $\mathrm{H}_{2}$ is produced and attached to the metals in the subsequent step (I2). In this last case, our DFT calculations corroborate the preference of $\mathrm{H}_{2}$ to interact via the $\mathrm{Ni}$ moiety in a singlet state before its final release, as demonstrated by the closer metal- $\mathrm{H}_{2}$ distances on average of $1.65 \AA$ (I2a s) vs $1.82 \AA$ (I2a t), $1.75 \AA$ (I2b s), and $1.74 \AA$ $(\mathrm{I} 2 \mathrm{~b} \mathrm{t})$.

Figure 2 describes the energy profile for the HER pathway at the SHE and under natural environment conditions followed by the active site in our [NiFe] hydrogenase model. As has been previously mentioned, triplet states are less stable than singlet states in all the cases in which both multiplicities can be described, but also the singlet reaction path has a lower energy demand for the thermodynamic rate-determining step than the triplet path. Focusing on the minimum energy path, two important characteristics can be highlighted. On the one hand, the addition of both $\mathrm{H}^{+} / \mathrm{e}^{-}$pairs to the reactive sulfur atom ( Ni-SI $I_{\mathrm{a}}$ to $\mathbf{I} 1$ and $\mathrm{Ni}-\mathrm{C}$ to $\mathrm{Ni}-\mathrm{R}$ ) indicates positive Gibbs free reaction energies at $298.15 \mathrm{~K}$ (hereafter simply referred as reaction energy), and the second addition appears as the highest reaction energy of the whole process (19.48 vs 19.72 $\mathrm{kcal} / \mathrm{mol}$ including the $\mathrm{pH}$ correction). On the other hand, the transfers toward the metal environment to produce the bridging 

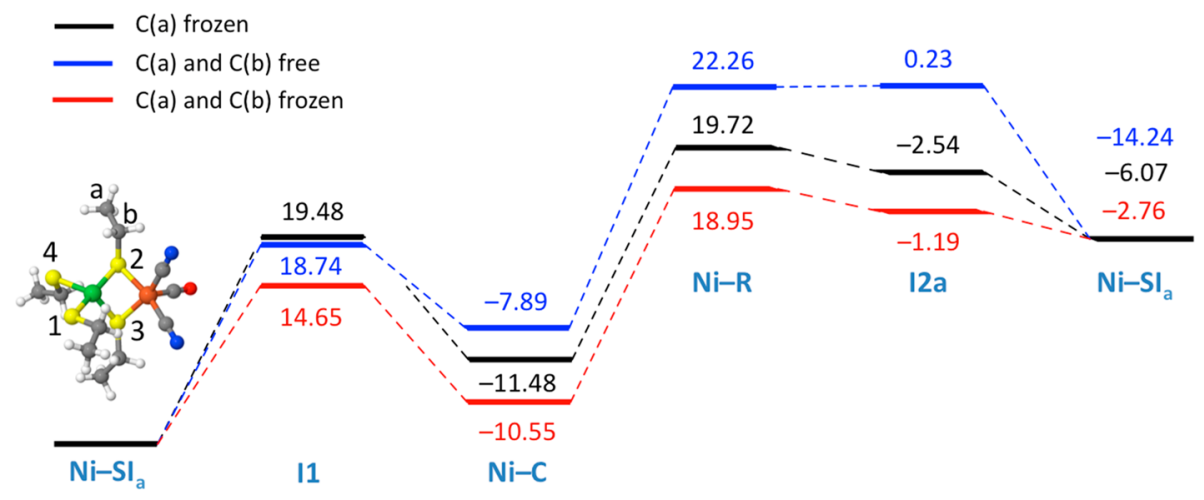

Figure 3. Energy profile, in units of $\mathrm{kcal} / \mathrm{mol}$, for the HER singlet pathway attending to three different models on the basis of carbon constraints. Relative energies are referred to the $\mathbf{N i}-\mathbf{S I}_{\mathrm{a}}$ state, in which $\Delta G=0 \mathrm{kcal} / \mathrm{mol}$. The $\mathrm{pH}$ corrections $(\mathrm{pH} 7)$ are also included in the energy profile for the natural environment of hydrogenases.

hydride and the sequestrated $\mathrm{H}_{2}$ molecule at $\mathrm{Ni}-\mathrm{C}$ and $\mathbf{I 2}$, respectively, are spontaneous processes. However, while for the first of these process $11.48 \mathrm{kcal} / \mathrm{mol}$ is released, in the second process the reaction energy only drops $2.54 \mathrm{kcal} / \mathrm{mol}$. Our interpretation for such a reaction energy results is based on the idea that the second $\mathrm{H}^{+} / \mathrm{e}^{-}$gain is more expensive than the first gain, because of the previous hydrogenation existing as a bridging hydride at $\mathrm{Ni}-\mathrm{C}$. We also suggest that this is the reason the second $\mathrm{H}$ transfer from the reactive sulfur to the bimetallic active site is less spontaneous than the first. In addition, the kinetic analysis suggests that the $\mathrm{H}_{2}$ formation is more expensive than the proton to hydride formation. Besides, the activation energy for the I1 to Ni-C step exhibits a barrier of $8.18 \mathrm{kcal} / \mathrm{mol}$ (TS1), while that for the Ni-R to I2a step is $12.96 \mathrm{kcal} / \mathrm{mol}$ (TS2), being smaller than the $19.72 \mathrm{kcal} / \mathrm{mol}$ required in the thermodynamic rate-determining step.

Finally, despite the fact that the molecular reactivity can often be explained through consideration of the highest occupied and lowest unoccupied molecular orbitals (HOMO and LUMO), the representation of such frontier orbitals in our case cannot fully explain the $2 \mathrm{H}^{+}+2 \mathrm{e}^{-} \rightarrow \mathrm{H}_{2}$ transformation route. Nevertheless, the LUMO in the $\mathbf{N i - S I}$ and $\mathbf{N i}-\mathbf{C}$ states are partially localized on the reactive sulfur atom. In addition, a clearer LUMO is located on the metal environment at I1, with a percentage of almost $51 \%$, which explains why the $\mathrm{H}$ is transferred into the $\mathrm{Ni}-\mathrm{H}-\mathrm{Fe}$ bridging position (see Figure $\mathrm{S} 1$ in the Supporting Information).

Role of the Cysteine Ligands on Ni. It is well-known that the reactivity displayed by enzymes is strongly related to their structure, including the protein environment, displacement/ substitution of inorganic ligands, or conformational fluctuations. Since the bimetallic active site involves exo- and endocyclic cysteines directly bound to it, imposition of structural constraints by freezing of the carbon skeleton can provide clear information about the structure-reactivity patterns.

In the previous section in which the role of multiplicity was explained, the distal carbon atom $(\mathrm{C}(\mathrm{a}))$ was frozen during optimization. Comparisons between this and a more constrained model, in which both carbons from the truncated cysteines skeleton are frozen $(\mathrm{C}(\mathrm{a})$ and $\mathrm{C}(\mathrm{b}))$, reveal that the reaction energy for the first hydrogenation gain, represented by the Ni-SI to I1 step, decreases by $4.83 \mathrm{kcal} / \mathrm{mol}$ (see Figure 3).

This reaction energy diminution is in contrast with the minor structural differences shown between $\mathbf{N i}-\mathbf{S I}_{\mathbf{a}}$ and $\mathbf{I 1}$ in both models; however, an important variation in the stabilization of the LUMO energy explains this fact. In relative terms, the HOMO-LUMO gap decreases by $4.27 \mathrm{kcal} / \mathrm{mol}$ (see the Supporting Information) in the totally frozen model. This important observation is in accord with the DFT investigations recently published by Bruschi et al., ${ }^{50}$ who found a similar difference in the frontier orbital behavior when comparing several $\mathrm{S}-\mathrm{Ni}-\mathrm{S}$ geometrical angles for the reverse path of the $\mathrm{H}_{2}$ binding ( $\mathbf{I} \mathbf{a}$ in our model) on the active site of [NiFe] hydrogenases. While for the rest of the steps small structural changes can be seen, no remarkable differences in HOMOLUMO energy gaps are found. Additionally, reaction energies slightly decrease by $0.77 \mathrm{kcal} / \mathrm{mol}$ when both models are compared.

The so-called free model, consisting of unconstrained truncated cysteine moieties during optimization, shows some differences worthy of mention. The first and most important

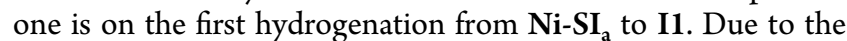
free movement of the carbon skeleton of the cysteine ligands, $\varphi_{\text {S2S1S3S4 }}$ dihedral angles vary from $-47^{\circ}$ in the partially frozen model to $-37^{\circ}$ in the unconstrained model at $\mathbf{N i - S I _ { a }}$. In other words, the sulfur environment attached to $\mathrm{Ni}$ evolves from a seesaw conformation into a more planar configuration. Second, at $\mathbf{I 1}$, the $(\mathrm{Ni})-\mathrm{SCH}_{2} \mathrm{CH}_{3}$ ligands experience important rotational distortions, with $A_{\mathrm{S} 1 \mathrm{NiS} 2}$ and $A_{\mathrm{S} 3 \mathrm{NiS} 4}$ differences of 48 and $9^{\circ}$. For Ni-SI $A_{\text {s1NiS2 }}$ has not experienced any important variation; however, $A_{\mathrm{S} 3 \mathrm{NiS} 4}$ differs by $23^{\circ}$ between both models.

The HOMO-LUMO gap increases by $6.30 \mathrm{kcal} / \mathrm{mol}$ in comparison with the partially frozen model, which is larger than the gap disparity between the total and partially frozen models, suggesting a larger difference between the reaction energies. However, a similar reaction energy can be seen for such step, with deviations of merely $0.74 \mathrm{kcal} / \mathrm{mol}$. According to the geometry distortion occurring in the free model, the small reaction energy difference is a result of the electron distribution and the geometric structure. Similarly, we can see an important energy difference when comparing the I1 and Ni-C steps; however, the HOMO-LUMO gap and positions remain quite similar. This indicates that the distortion in the carbon skeleton conformation of the active site, which is caused by a different $\mathrm{Ni}$ coordination geometry in the different states, is another important reason for this energy difference in addition to the frontier orbitals. Additionally, for the final $\mathrm{H}_{2}$ release step (I2), the HOMO-LUMO gap plays a minor role in comparison with the geometric distortion. On the other hand, the geometries of the protein-metal environment for the intermediate $\mathrm{Ni}-\mathrm{C}, \mathrm{Ni}$ - 


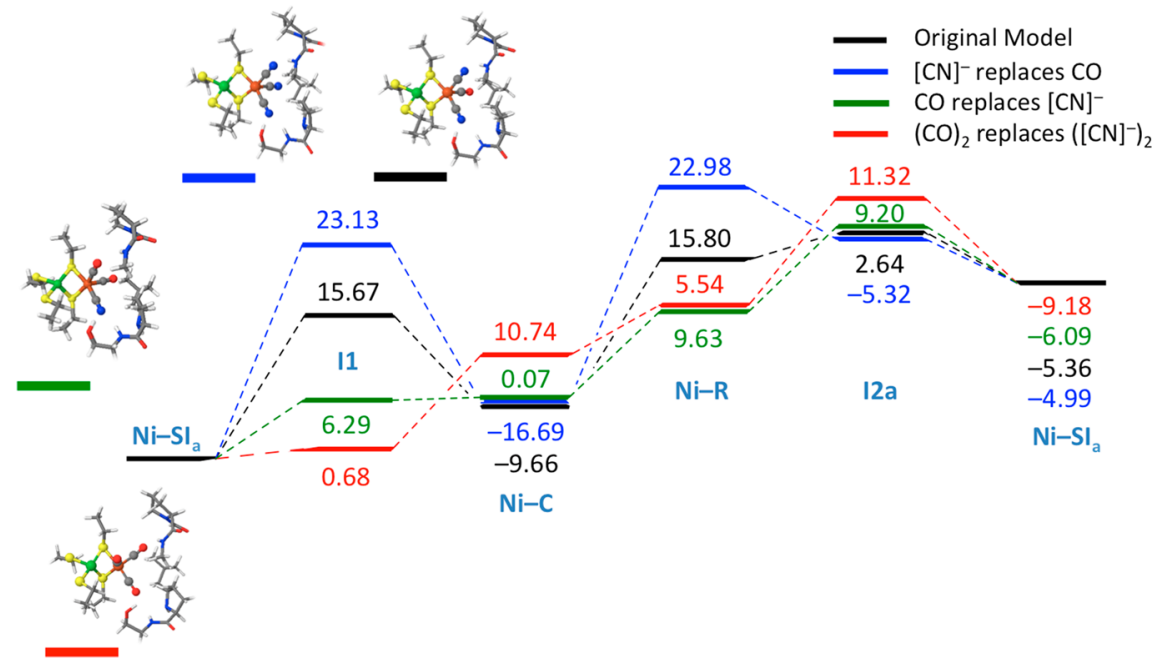

Figure 4. Gibbs free energy profile, in units of $\mathrm{kcal} / \mathrm{mol}$, for the HER singlet pathway by replacement of the inorganic ligands attached to Fe. Relative energies are referred to the Ni-SI ${ }_{\mathrm{a}}$ state, in which $\Delta G=0 \mathrm{kcal} / \mathrm{mol}$. The $\mathrm{pH}$ corrections $(\mathrm{pH} 7)$ are also included in the energy profile for the natural environment of hydrogenases.

R, and $\mathbf{2}$ steps surprisingly exhibit high similarity with the constrained models (both one and two carbons frozen), which seems to be a consequence of the hydride $/ \mathrm{H}_{2}$ interacting with the metals.

Role of Inorganic Ligands on Fe. $\mathrm{CO}$ and $[\mathrm{CN}]^{-}$ligands have been detected on the active site bonded to the Fe center in both $[\mathrm{NiFe}]$ and $[\mathrm{FeFe}]$ hydrogenases. ${ }^{8}$ Both the $\mathrm{CO}$ and $[\mathrm{CN}]^{-}$species are strong-field ligands that intensely affect the splitting of the d-like orbitals on the metal and therefore contribute to the stabilization of low oxidation states of $\mathrm{Fe}$, indicating the significant role they might play in the catalytic cycle. Although they are very close in the spectrochemical series, they must have different effects on the active site. Previous work on $[\mathrm{FeFe}]$ hydrogenases has investigated the energy required for the $\mathrm{CO}$ and $[\mathrm{CN}]^{-}$redisposition and the electronic structure change for the $[\mathrm{CN}]^{-}$replacement by $\mathrm{CO} .^{65,66}$ In our work, these two types of ligands have been replaced by each other in order to study their influence on the reaction pathway (see Figure 4). In addition, amino acids around the inorganic ligands are included in our calculation model, which lead to a slight difference in the energy profile, as the energies required for the two thermodynamic ratedetermining $\mathrm{H}^{+} / \mathrm{e}^{-}$added steps decrease by $\sim 4 \mathrm{kcal} / \mathrm{mol}$ with respect to the initial model without the inclusion of the Pro478, Leu482, Pro501, and Ser502 residues (compare Figures 2 and 4). However, the trends of the profile remain similar. Therefore, the amino acids around could promote the HER, although those steps that presented spontaneous reaction energies are hypothesized to not be strongly affected by the amino acid environment.

The replacement of the two $[\mathrm{CN}]^{-}$ligands by two neutral $\mathrm{CO}$ ligands brings a remarkable change in trend to the reaction energy profile for the whole (highlighted in red at Figure 4). On the one hand, it reduces the energy difference for the first $\mathrm{H}^{+} / \mathrm{e}^{-}$pair gain. While for the original model the energy input for the $\mathbf{N i}-\mathbf{S I}_{\mathrm{a}}$ to I1 step was $15.67 \mathrm{kcal} / \mathrm{mol}$, the effect of these two $\mathrm{CO}$ replacements leads to an almost no-energy-required process with the injection of merely $0.68 \mathrm{kcal} / \mathrm{mol}$. The frontier orbitals show that the HOMO-LUMO gap dramatically decreases by around $8.44 \mathrm{kcal} / \mathrm{mol}$ with respect to the original gap, which might be one of the reasons for the change in the reaction energy. On the other hand, the proton seems to experience some difficulty in transferring toward the bridging position in the bimetallic environment $(10.74 \mathrm{kcal} / \mathrm{mol})$, which was spontaneous in the original model. In addition, the second $\mathrm{H}^{+} / \mathrm{e}^{-}$pair injection to this "modified-on-Fe" active site newly displays a significant energy change of $5.54 \mathrm{kcal} / \mathrm{mol}$ vs the $15.80 \mathrm{kcal} / \mathrm{mol}$ demanded in the original model. The limiting thermodynamic step, located on the Ni-R species obtained in the original model, has varied. Notwithstanding, it is transferred to the sequestrated $\mathrm{H}_{2}$ on $\mathrm{Ni}$ (Ni-R to I2) with a nonspontaneous reaction energy equal to $11.32 \mathrm{kcal} / \mathrm{mol}$. In other words, while the two nonspontaneous $\mathrm{H}$ addition steps have become easier by the two $[\mathrm{CN}]^{-}$to two $\mathrm{CO}$ replacements, the bridging hydride formation and the production of $\mathrm{H}_{2}$ to be captured on $\mathrm{Ni}$ become nonspontaneous and result in the severest reaction energy of the whole reaction.

In this sense, the substitution of just one $\mathrm{CO}$ for one of the $[\mathrm{CN}]^{-}$ligands (indicated in green at Figure 4) newly confirms that the first hydrogenation step (Ni-SI $\mathbf{a}_{\mathrm{a}}$ to $\mathbf{I 1}$ ) becomes less nonspontaneous with an energy requirement decreasing to 6.29 $\mathrm{kcal} / \mathrm{mol}$ in comparison with the original model. Very smooth thermodynamics can be analyzed for the subsequent I1 to Ni-C step, with a reaction energy as low as $0.07 \mathrm{kcal} / \mathrm{mol}$. Then, similar to the energy drop for the first hydrogenation, the energy demand for the Ni-C to Ni-R step drops from 15.80 to $9.63 \mathrm{kcal} / \mathrm{mol}$. Finally, the severest reaction energy is found for the dihydrogen intermediate formation, requiring $9.20 \mathrm{kcal} / \mathrm{mol}$ for this. In view of these results, it seems evident that the elimination of $[\mathrm{CN}]^{-}$moieties in favor of $\mathrm{CO}$ ligand substitution supposes dramatic changes for the thermodynamics of the HER catalyzed by $[\mathrm{NiFe}]$ hydrogenases. It is worth mentioning that not only the energy required for the thermodynamic rate-limiting step decreases but also this kind of replacement is spontaneous, with $12.95 \mathrm{kcal} / \mathrm{mol}$ released under vacuum conditions.

A completely different outcome appears when the only neutral $\mathrm{CO}$ ligand in the original model is substituted by another $[\mathrm{CN}]^{-}$(blue profile at Figure 4 ). The energy profile exhibits a similar trend with respect to the original model: i.e., $\mathrm{H}^{+} / \mathrm{e}^{-}$injections on the reactive $\mathrm{S}$ atom $\left(\mathbf{N i}-\mathbf{S I}_{\mathbf{a}}\right.$ to $\mathbf{I} \mathbf{1}$ and $\mathbf{N i}-\mathbf{C}$ 
to $\mathbf{N i - R}$ ) are nonspontaneous, while the transfer of $\mathrm{H}$ to become a bridging hydride (II to $\mathrm{Ni}-\mathrm{C}$ ) and the production of $\mathrm{H}_{2}$ to be captured on $\mathrm{Ni}$ (Ni-R to I2a) are spontaneous processes. However, both the injection and release of energy show larger reaction energies in both senses: that is, nonspontaneous processes become more "expensive" in terms of energy (23.13 and $22.98 \mathrm{kcal} / \mathrm{mol}$ ) and spontaneous processes release more energy than in the original model $(-16.69$ and $-5.32 \mathrm{kcal} / \mathrm{mol})$.

Concerning the redox states of $\mathrm{Ni}$ and $\mathrm{Fe}$ in the original model, the Mulliken spin densities for the I1 state are 0.6382 and -0.0806 , respectively. The substitution of two $[\mathrm{CN}]^{-}$with two CO leads to spin densities of 0.4766 and 0.0288 , while for the case of substitution of just one $[\mathrm{CN}]^{-}$by one $\mathrm{CO}$, they are 0.5651 and -0.0399 . Finally, in the case in which one $[\mathrm{CN}]^{-}$ replaces one $\mathrm{CO}$ ligand, such densities are 0.6155 and 0.0004 . Hence, we can hypothesize that the metals remain as $\mathrm{Ni}(\mathrm{I})$ and $\mathrm{Fe}(\mathrm{II})$ after any substitution.

It is surprising to note how changes on the $\mathrm{Fe}$ environment produce a major influence on the catalytic path of $[\mathrm{NiFe}]$ hydrogenases, despite the fact that $\mathrm{Fe}$ has a little-recognized role in comparison with $\mathrm{Ni}$. The latter is the link between the active site and the protein environment through endocyclic cysteine residues, providing the electrons in the transformation of proton into hydride, where $\mathrm{H}_{2}$ prefers to bind until its final release. As the $[\mathrm{CN}]^{-}$and $\mathrm{CO}$ ligands commonly exist in bioinspired catalysts, ${ }^{67}$ therefore the replacement of each might be able to tune the energies for the $\mathrm{H}^{+} / \mathrm{e}^{-}$added and the $\mathrm{H}_{2}$ formation.

\section{SUMMARY AND CONCLUSIONS}

In summary, DFT investigations of the HER mechanism catalyzed by the active site of $[\mathrm{NiFe}]$ hydrogenases indicate that the minimum energy path follows a singlet multiplicity route. The addition of the $\mathrm{H}^{+}$moieties on the reactive sulfur atom from one of the exocyclic cysteine residues are nonspontaneous processes in terms of the calculated Gibbs free reaction energies at room temperature. The $\mathbf{N i - C}$ to $\mathbf{N i - R}$ process exhibits the largest thermodynamic impediment of the whole reaction. In contrast, the proton migrations to become a bridging hydride (I1 to Ni-C) and to produce $\mathrm{H}_{2}$ to be captured on $\mathrm{Ni}$ (Ni-R to I2a) are spontaneous processes. We hypothesize that the second step is a less spontaneous step due to a previously existing bridging hydride, which obstructs the second transfer. Even concerning kinetics, the largest and limiting ratedetermining step is hypothesized for the $\mathbf{N i - C}$ to $\mathbf{N i - R}$ step, with $19.72 \mathrm{kcal} / \mathrm{mol}$ energy required in a natural environment.

The protein ligand confinement appears to be important in the HER path followed by [NiFe] hydrogenases. Our models, being constrained in different degrees, reveal that the protein environment, as it is in Nature, seems to be more efficient for the catalysis of $\mathrm{H}_{2}$ production (and cleavage). Energy differences between the partially and totally frozen models exhibit a decrease of 4.83 and $0.77 \mathrm{kcal} / \mathrm{mol}$ for the Ni-SI to I1 and Ni-C to Ni-R steps, respectively.

Remarkable differences can be seen when the inorganic ligands attached to $\mathrm{Fe}$ are replaced by each other. This replacement leads to dramatic changes in the reaction energies. While the presence of totally neutral CO ligands on Fe helps the $\mathrm{H}^{+} / \mathrm{e}^{-}$injection and inhibits the $\mathrm{H}^{+}$to hydride and the $\mathrm{H}_{2}$ sequestration on $\mathrm{Ni}$ steps, the removal of $\mathrm{CO}$ by another $[\mathrm{CN}]^{-}$ligand penalizes the classical Ni-C to Ni-R limiting step. Finally, these dramatic changes could serve as strategies for the design of novel catalysts based on bioinspired molecules for efficient $\mathrm{H}_{2}$ production.

\section{ASSOCIATED CONTENT}

\section{Supporting Information}

The Supporting Information is available free of charge on the ACS Publications website at DOI: 10.1021/acscatal.6b01359.

Cartesian coordinates for the different structures in all models as well as HOMO/LUMO interpretations (PDF)

\section{AUTHOR INFORMATION}

\section{Corresponding Authors}

*D.R.M.: tel, (+61) 39905 4540; fax, (+61) 39905 4597; email, Douglas.MacFarlane@monash.edu.

*C.S.: tel, (+61) 39902 9916; fax, (+61) 39905 4597; e-mail, Chenghua.Sun@monash.edu.

\section{Notes}

The authors declare no competing financial interest.

\section{ACKNOWLEDGMENTS}

The authors acknowledge the Australian Research Council (ARC) for its support through the Australian Centre of Excellence for Electromaterials Science (ACES), Discovery Project (DP130100268), Future Fellowship (CS, FT130100076), and Laureate Fellowship (DRM) schemes. The National Computational Infrastructure (NCI), which is supported by the Australian Government, and the Monash eResearch Centre and eSolutions-Research Support Services through the use of the Monash MASSIVE clusters and Campus HPC Cluster are also acknowledged for providing the computational resources. Gratitude is also due to Dr. Ekaterina Pas for her advices in the development of the present work.

\section{REFERENCES}

(1) Karl, T. R.; Trenberth, K. E. Science 2003, 302, 1719-1723.

(2) Betts, R. A.; Boucher, O.; Collins, M.; Cox, P. M.; Falloon, P. D.; Gedney, N.; Hemming, D. L.; Huntingford, C.; Jones, C. D.; Sexton, D. M. H.; Webb, M. J. Nature 2007, 448, 1037-1041.

(3) Meyer, J. Nature 2008, 455, 733-733.

(4) Nørskov, J. K.; Bligaard, T.; Logadottir, A.; Kitchin, J. R.; Chen, J. G.; Pandelov, S.; Stimming, U. J. Electrochem. Soc. 2005, 152, J23-J26.

(5) Wang, M.; Chen, L.; Sun, L. Energy Environ. Sci. 2012, 5, 67636778.

(6) Madden, C.; Vaughn, M. D.; Díez-Pérez, I.; Brown, K. A.; King P. W.; Gust, D.; Moore, A. L.; Moore, T. A. J. Am. Chem. Soc. 2012, 134, 1577-1582.

(7) Vignais, P. M.; Billoud, B. Chem. Rev. 2007, 107, 4206-4272.

(8) Lubitz, W.; Ogata, H.; Rudiger, O.; Reijerse, E. Chem. Rev. 2014, 114, 4081-4148.

(9) Burgdorf, T.; Lenz, O.; Buhrke, T.; van der Linden, E.; Jones, A. K.; Albracht, S. P. J.; Friedrich, B. J. Mol. Microbiol. Biotechnol. 2006, 10, 181-196.

(10) Garcin, E.; Vernede, X.; Hatchikian, E. C.; Volbeda, A.; Frey, M.; Fontecilla-Camps, J. C. Structure 1999, 7, 557-566.

(11) Fontecilla-Camps, J. C.; Volbeda, A.; Cavazza, C.; Nicolet, Y. Chem. Rev. 2007, 107, 4273-4303.

(12) Rippers, Y.; Horch, M.; Hildebrandt, P.; Zebger, I.; Mroginski, M. A. ChemPhysChem 2012, 13, 3852-3856.

(13) Ogata, H.; Hirota, S.; Nakahara, A.; Komori, H.; Shibata, N.; Kato, T.; Kano, K.; Higuchi, Y. Structure 2005, 13, 1635-1642.

(14) Volbeda, A.; Martin, L.; Cavazza, C.; Matho, M.; Faber, B. W.; Roseboom, W.; Albracht, S. P.; Garcin, E.; Rousset, M.; FontecillaCamps, J. C. JBIC, J. Biol. Inorg. Chem. 2005, 10, 239-249. 
(15) van Gastel, M.; Stein, M.; Brecht, M.; Schröder, O.; Lendzian, F.; Bittl, R.; Ogata, H.; Higuchi, Y.; Lubitz, W. JBIC, J. Biol. Inorg. Chem. 2006, 11, 41-51.

(16) Pardo, A.; De Lacey, A.; Fernández, V.; Fan, Y.; Hall, M. JBIC, J. Biol. Inorg. Chem. 2007, 12, 751-760.

(17) Siegbahn, P. E. M. C. R. Chim. 2007, 10, 766-774.

(18) Ogata, H.; Kellers, P.; Lubitz, W. J. Mol. Biol. 2010, 402, 428444.

(19) Volbeda, A.; Martin, L.; Barbier, E.; Gutiérrez-Sanz, O.; De Lacey, A. L.; Liebgott, P.-P.; Dementin, S.; Rousset, M.; FontecillaCamps, J. C. JBIC, J. Biol. Inorg. Chem. 2015, 20, 11-22.

(20) Bleijlevens, B.; Faber, B.; Albracht, S. JBIC, J. Biol. Inorg. Chem. 2001, 6, 763-769.

(21) Fichtner, C.; Laurich, C.; Bothe, E.; Lubitz, W. Biochemistry 2006, 45, 9706-9716.

(22) De Lacey, A. L.; Fernández, V. M.; Rousset, M.; Cammack, R. Chem. Rev. 2007, 107, 4304-4330.

(23) Lubitz, W.; Reijerse, E.; van Gastel, M. Chem. Rev. 2007, 107, 4331-4365.

(24) Pandelia, M.-E.; Ogata, H.; Currell, L. J.; Flores, M.; Lubitz, W. Biochim. Biophys. Acta, Bioenerg. 2010, 1797, 304-313.

(25) Lill, S. O. N.; Siegbahn, P. E. M. Biochemistry 2009, 48, 10561066.

(26) Niu, S.; Thomson, L. M.; Hall, M. B. J. Am. Chem. Soc. 1999, 121, 4000-4007.

(27) Li, S.; Hall, M. B. Inorg. Chem. 2001, 40, 18-24.

(28) Foerster, S.; Stein, M.; Brecht, M.; Ogata, H.; Higuchi, Y.; Lubitz, W. J. Am. Chem. Soc. 2003, 125, 83-93.

(29) Foerster, S.; Gastel, M.; Brecht, M.; Lubitz, W. JBIC, J. Biol. Inorg. Chem. 2005, 10, 51-62.

(30) Wu, H.; Hall, M. B. C. R. Chim. 2008, 11, 790-804.

(31) Pandelia, M. E.; Infossi, P.; Stein, M.; Giudici-Orticoni, M. T.; Lubitz, W. Chem. Commun. 2012, 48, 823-825.

(32) Kampa, M.; Lubitz, W.; van Gastel, M.; Neese, F. JBIC, J. Biol. Inorg. Chem. 2012, 17, 1269-1281.

(33) Pardo, A.; De Lacey, A.; Fernández, V.; Fan, H.-J.; Fan, Y.; Hall, M. JBIC, J. Biol. Inorg. Chem. 2006, 11, 286-306.

(34) De Lacey, A. L.; Pardo, A.; Fernandez, V. M.; Dementin, S.; Adryanczyk-Perrier, G.; Hatchikian, E. C.; Rousset, M. JBIC, J. Biol. Inorg. Chem. 2004, 9, 636-642.

(35) Kramer, T.; Kampa, M.; Lubitz, W.; van Gastel, M.; Neese, F. ChemBioChem 2013, 14, 1898-1905.

(36) Ogata, H.; Nishikawa, K.; Lubitz, W. Nature 2015, 520, 571574.

(37) Ogata, H.; Kramer, T.; Wang, H.; Schilter, D.; Pelmenschikov, V.; van Gastel, M.; Neese, F.; Rauchfuss, T. B.; Gee, L. B.; Scott, A. D.; Yoda, Y.; Tanaka, Y.; Lubitz, W.; Cramer, S. P. Nat. Commun. 2015, 6, 7890.

(38) Keith, J. M.; Hall, M. B. Inorg. Chem. 2010, 49, 6378-6380.

(39) Surerus, K. K.; Chen, M.; van der Zwaan, J. W.; Rusnak, F. M.; Kolk, M.; Duin, E. C.; Albracht, S. P. J.; Muenck, E. Biochemistry 1994, 33, 4980-4993.

(40) Volbeda, A.; Garcin, E.; Piras, C.; de Lacey, A. L.; Fernandez, V. M.; Hatchikian, E. C.; Frey, M.; Fontecilla-Camps, J. C. J. Am. Chem. Soc. 1996, 118, 12989-12996.

(41) De Lacey, A.; Stadler, C.; Fernandez, V.; Hatchikian, C.; Fan, H.-J.; Li, S.; Hall, M. JBIC, J. Biol. Inorg. Chem. 2002, 7, 318-326.

(42) Bleijlevens, B.; van Broekhuizen, F.; De Lacey, A.; Roseboom, W.; Fernandez, V.; Albracht, S. J. JBIC, J. Biol. Inorg. Chem. 2004, 9, $743-752$.

(43) Bruschi, M.; Zampella, G.; Fantucci, P.; De Gioia, L. Coord. Chem. Rev. 2005, 249, 1620-1640.

(44) Schröder, O.; Bleijlevens, B.; de Jongh, T.; Chen, Z.; Li, T.; Fischer, J.; Förster, J.; Friedrich, C.; Bagley, K.; Albracht, S. J.; Lubitz, W. JBIC, J. Biol. Inorg. Chem. 2007, 12, 212-233.

(45) Wang, H.; Ralston, C. Y.; Patil, D. S.; Jones, R. M.; Gu, W.; Verhagen, M.; Adams, M.; Ge, P.; Riordan, C.; Marganian, C. A.; Mascharak, P.; Kovacs, J.; Miller, C. G.; Collins, T. J.; Brooker, S.;
Croucher, P. D.; Wang, K.; Stiefel, E. I.; Cramer, S. P. J. Am. Chem. Soc. 2000, 122, 10544-10552.

(46) Wang, C. P.; Franco, R.; Moura, J. J.; Moura, I.; Day, E. P. J. Biol. Chem. 1992, 267, 7378-7380.

(47) Dole, F.; Fournel, A.; Magro, V.; Hatchikian, E. C.; Bertrand, P.; Guigliarelli, B. Biochemistry 1997, 36, 7847-7854.

(48) Siegbahn, P. E. M.; Tye, J. W.; Hall, M. B. Chem. Rev. 2007, 107, 4414-4435.

(49) Delcey, M. G.; Pierloot, K.; Phung, Q. M.; Vancoillie, S.; Lindh, R.; Ryde, U. Phys. Chem. Chem. Phys. 2014, 16, 7927-7938.

(50) Bruschi, M.; Tiberti, M.; Guerra, A.; De Gioia, L. J. Am. Chem. Soc. 2014, 136, 1803-1814.

(51) Perdew, J. P. Phys. Rev. B: Condens. Matter Mater. Phys. 1986, 33, $8822-8824$

(52) Becke, A. D. Phys. Rev. A: At., Mol., Opt. Phys. 1988, 38, 30983100.

(53) Weigend, F.; Ahlrichs, R. Phys. Chem. Chem. Phys. 2005, 7, $3297-3305$

(54) Kudin, K. N.; Scuseria, G. E.; Cancès, E. J. Chem. Phys. 2002, $116,8255-8261$.

(55) Grimme, S.; Antony, J.; Ehrlich, S.; Krieg, H. J. Chem. Phys. 2010, 132, 154104.

(56) Nørskov, J. K.; Rossmeisl, J.; Logadottir, A.; Lindqvist, L.; Kitchin, J. R.; Bligaard, T.; Jónsson, H. J. Phys. Chem. B 2004, 108, 17886-17892.

(57) Skulason, E.; Karlberg, G. S.; Rossmeisl, J.; Bligaard, T.; Greeley, J.; Jonsson, H.; Norskov, J. K. Phys. Chem. Chem. Phys. 2007, 9, 32413250.

(58) Rossmeisl, J.; Qu, Z. W.; Zhu, H.; Kroes, G. J.; Nørskov, J. K. J. Electroanal. Chem. 2007, 607, 83-89.

(59) Frisch, M. J.; Trucks, G. W.; Schlegel, H. B.; Scuseria, G. E.; Robb, M. A.; Cheeseman, J. R.; Scalmani, G.; Barone, V.; Mennucci, B.; Petersson, G. A.; Nakatsuji, H.; Caricato, M.; Li, X.; Hratchian, H. P.; Izmaylov, A. F.; Bloino, J.; Zheng, G.; Sonnenberg, J. L.; Hada, M.; Ehara, M.; Toyota, K.; Fukuda, R.; Hasegawa, J.; Ishida, M.; Nakajima, T.; Honda, Y.; Kitao, O.; Nakai, H.; Vreven, T.; Montgomery, J. A., Jr.; Peralta, J. E.; Ogliaro, F.; Bearpark, M.; Heyd, J. J.; Brothers, E.; Kudin, K. N.; Staroverov, V. N.; Kobayashi, R.; Normand, J.; Raghavachari, K.; Rendell, A.; Burant, J. C.; Iyengar, S. S.; Tomasi, J.; Cossi, M.; Rega, N.; Millam, N. J.; Klene, M.; Knox, J. E.; Cross, J. B.; Bakken, V.; Adamo, C.; Jaramillo, J.; Gomperts, R.; Stratmann, R. E.; Yazyev, O.; Austin, A. J.; Cammi, R.; Pomelli, C.; Ochterski, J. W.; Martin, R. L.; Morokuma, K.; Zakrzewski, V. G.; Voth, G. A.; Salvador, P.; Dannenberg, J. J.; Dapprich, S.; Daniels, A. D.; Farkas, Ö.; Foresman, J. B.; Ortiz, J. V.; Cioslowski, J.; Fox, D. J. Gaussian09 (Revision D.01); Gaussian, Inc., Wallingford, CT, 2009.

(60) Protein Data Bank: http://www.rcsb.org.

(61) Higuchi, Y.; Ogata, H.; Miki, K.; Yasuoka, N.; Yagi, T. Structure 1999, 7, 549-556.

(62) Qiu, S.; Azofra, L. M.; MacFarlane, D. R.; Sun, C. Phys. Chem. Chem. Phys. 2016, 18, 15369-15374.

(63) Jayapal, P.; Robinson, D.; Sundararajan, M.; Hillier, I. H.; McDouall, J. J. W. Phys. Chem. Chem. Phys. 2008, 10, 1734-1738.

(64) Becke, A. D. J. Chem. Phys. 1993, 98, 5648-5652.

(65) Greco, C.; Bruschi, M.; Fantucci, P.; Ryde, U.; De Gioia, L. Chem. - Eur. J. 2011, 17, 1954-1965.

(66) Bruschi, M.; Greco, C.; Bertini, L.; Fantucci, P.; Ryde, U.; Gioia, L. D. J. Am. Chem. Soc. 2010, 132, 4992-4993.

(67) Felton, G. A. N.; Mebi, C. A.; Petro, B. J.; Vannucci, A. K.; Evans, D. H.; Glass, R. S.; Lichtenberger, D. L. J. Organomet. Chem. 2009, 694, 2681-2699. 